\title{
Silk Fibroin Porous Scaffolds Loaded with a Slow-Releasing Hydrogen Sulfide Agent (GYY4137) for Applications of Tissue Engineering
}

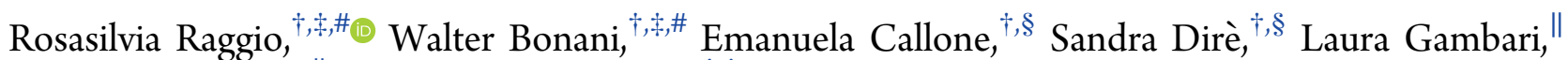 \\ Francesco Grassi, ${ }^{*}, \|$ and Antonella Motta ${ }^{*},+,+$ \\ ${ }^{\dagger}$ Department of Industrial Engineering, University of Trento, Via Sommarive 9, 38123 Trento, Italy \\ ${ }^{\ddagger}$ BIOtech Research Center and European Institute of Excellence on Tissue Engineering and Regenerative Medicine, Via delle Regole \\ 101, 38123 Trento, Italy \\ §"Klaus Muller” Magnetic Resonance Laboratory, Department of Industrial Engineering, University of Trento, Via Sommarive 9, \\ 38123 Trento, Italy \\ "RAMSES Laboratory, IRCCS Istituto Ortopedico Rizzoli, Via di Barbiano 1/10, 40136 Bologna, Italy
}

\begin{abstract}
Hydrogen sulfide $\left(\mathrm{H}_{2} \mathrm{~S}\right)$ is a physiological gasotransmitter known to possess a regulatory role in several tissues, including bone. The exogenous administration by injection of solutions of $\mathrm{H}_{2} \mathrm{~S}$-releasing compounds (e.g., GYY4137) has been previously investigated as a novel therapeutic approach for the treatment of bone diseases. Here, GYY4137 was embedded into fibroin sponges, previously shown to be suitable as scaffolds for bone, thanks to their biocompatibility, scalable porous structure, and biodegradability rate. Fibroin porous scaffolds were produced by solvent casting and the particulate leaching method, and GYY4137 was successively incorporated by using dimethyl sulfoxide (DMSO) as vehicle. The process used to produce GYY4137-loaded scaffolds allowed the incorporation of different controlled amounts of GYY4137 into fibroin matrices. The loading

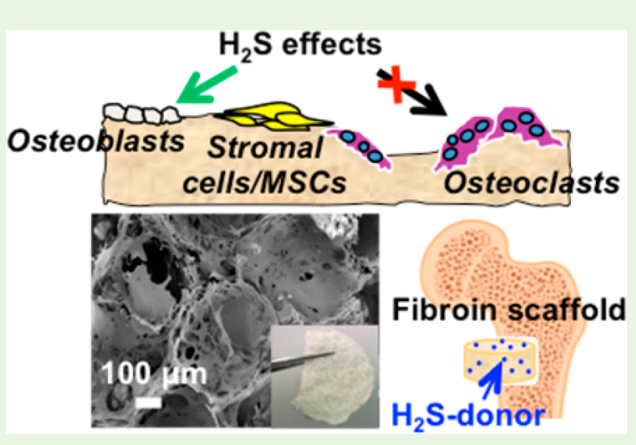
process preserved the properties of the system components in the final products, as assessed by SEM, FT-IR, NMR, and different thermal analyses techniques. Release of $\mathrm{H}_{2} \mathrm{~S}$ from GYY4137 incorporated into the scaffolds was monitored upon incubation in saline solution at physiological $\mathrm{pH}: \mathrm{H}_{2} \mathrm{~S}$-release kinetic was found to be dependent on the amount of GYY4137. To ensure biocompatibility, mouse fibroblasts and human primary bone marrow stromal cells were seeded onto scaffolds, and short-term viability assays were performed. Results showed that the GYY4137-loaded scaffold did not induce cytotoxicity in any of the cell type tested. Our findings demonstrate that embedding an $\mathrm{H}_{2} \mathrm{~S}$-releasing donor in silk fibroin scaffold is a suitable strategy to achieve a long-lasting release of $\mathrm{H}_{2} \mathrm{~S}$ that preserves cell viability and allows local delivery at sites of tissue injury.
\end{abstract}

KEYWORDS: hydrogen sulfide, GYY4137, silk fibroin, scaffold, bone tissue engineering

\section{INTRODUCTION}

Hydrogen sulfide $\left(\mathrm{H}_{2} \mathrm{~S}\right)$ is known to be physiologically present in mammalian tissues, produced in nanomolar concentrations by cells, and is nowadays included in the family of the endogenous gaseous messenger molecules, or gasotransmitters, together with nitric oxide (NO) and carbon monoxide (CO). ${ }^{1}$ The most relevant source of endogenous $\mathrm{H}_{2} \mathrm{~S}$ is generated from the amino acid L-cysteine by the combined catalytic activity of the enzymes cystathionine $\beta$-synthase (CBS) and cystathionine $\gamma$-lyase (CSE), both involved in methionine and in dietary cysteine metabolic pathways. ${ }^{2}$

In the last 20 years, starting from the discoveries of Abe and Kimura in $1996,{ }^{3}$ concentration levels of $\mathrm{H}_{2} \mathrm{~S}$ in different tissues have been investigated, and some of its biochemical and molecular processes have been clarified, providing scientists the opportunity to appreciate it as an essential ubiquitous modulator in the homeostasis of various tissues and organs, such as the brain, blood vessels, and the gastrointestinal tract. $^{3-5}$ The biological role of $\mathrm{H}_{2} \mathrm{~S}$ also extends to bone development and function. It was shown that exogenous $\mathrm{H}_{2} \mathrm{~S}$, in concentrations ranging between 50 and $200 \mu \mathrm{mol} / \mathrm{L}$, stimulated osteogenesis from human bone marrow stromal cells (hMSCs), by controlling $\mathrm{Ca}^{2+}$ influx through their ion channels, and dose-dependently inhibited human osteoclasts (hOCs) differentiation and function, as revealed by the capability to break down a mineral substrate. ${ }^{6,7}$

These findings suggest that exogenously administered $\mathrm{H}_{2} \mathrm{~S}$, may have a therapeutic role in the treatment of bone diseases, such as fractures, bone loss, and erosion due to injuries, osteoporosis, and complications due to surgical operations. ${ }^{7,8}$

Two of the most commonly used donors of $\mathrm{H}_{2} \mathrm{~S}$ are sodium hydrosulfide (NaHS) and ( $p$-methoxyphenyl)morpholino-

Received: February 22, 2018

Accepted: July 6, 2018

Published: July 6, 2018 
phosphinodithioic acid (GYY4137). In particular, GYY4137 possesses a relatively slow $\mathrm{H}_{2} \mathrm{~S}$-release kinetic compared to $\mathrm{NaHS}$, making it more suitable for the exogenous administration of $\mathrm{H}_{2} \mathrm{~S}$ in in vitro and in vivo experiments. ${ }^{9,10}$ Previous works reported that GYY4137 decomposes by hydrolysis, releasing low amounts of soluble $\mathrm{H}_{2} \mathrm{~S}$ gas in aqueous solution over a sustained period of time, in a temperature and $\mathrm{pH}$ dependent manner. ${ }^{11}$ Moreover, $\mathrm{H}_{2} \mathrm{~S}$ release from GYY4137 was shown to be a L-cysteine-activated mechanism, meaning that, in the presence of a biological thiol, such as L-cysteine, $\mathrm{H}_{2} \mathrm{~S}$ release became significant, nevertheless remaining slow and prolonged. ${ }^{12,13}$

In previously published studies, GYY4137 was administered systemically by injection to regulate, restore, and maintain $\mathrm{H}_{2} \mathrm{~S}$ concentration levels in solution in in vitro experiments, or in

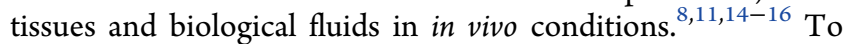
the best of our knowledge, a 3D system to achieve localized and sustained release of $\mathrm{H}_{2} \mathrm{~S}$ has not been explored before.

The aims of the present study were the realization and the characterization of an engineered scaffold combined with GYY4137, and the evaluation of its ability to provide a local release of $\mathrm{H}_{2} \mathrm{~S}$ in a biologic environment. These steps of preliminary validation are mandatory prior to evaluate the scaffold-dependent properties in inducing bone formation.

Various materials and fabrication techniques have been employed for the production of scaffolds for bone tissue engineering. ${ }^{17}$ Among the material sources, silkworm cocoons have been extensively exploited for the extraction of silk fibroin (SF), the structural protein constituting the core of silk fibers. In fact, fibroin was successfully used as suture material for centuries and is nowadays appreciated to form biomaterials for different medical uses. ${ }^{18}$ Starting from SF aqueous solutions and using simple, environmentally safe, and low-cost processing routes, various SF-based constructs and 3D frameworks could be prepared. ${ }^{19}$ The protein conformation, the crystallinity and the morphology conferred on SF during the fabrication of the biomaterial have a strong impact on the biological properties. In particular, 3D SF-based porous constructs, produced by salt leaching, demonstrated great biocompatibility as scaffolds for bone tissue engineering, thanks to the ability to enhance cell attachment, proliferation, and migration, the biodegradability properties, and the morphology, in terms of quality and degree of porosity. ${ }^{20-24}$ In different experiments, SF scaffolds were shown to be osteoconductive, by promoting in vitro osteogenesis in a range of bone-related cell types, ${ }^{25-28}$ and supporting the formation of new bone tissue when implanted in vivo. ${ }^{29,30}$ In addition, thanks to the stability and the flexibility of these materials, various modifications of SF scaffolds have been generated with chemical, structural, and biological innovations, or they were successfully combined with various bioactive agents and growth factors, ${ }^{31-33}$ with the final goal of enhancing the osteoinductive properties and the regenerative potentials.

Starting from this evidence, this manuscript describes a novel type of SF scaffold loaded with the $\mathrm{H}_{2} \mathrm{~S}$ donor GYY4137, intended to operate as $\mathrm{H}_{2} \mathrm{~S}$ releasing system to be used in the near future in bone regeneration studies. With this goal, highly porous silk fibroin matrices were produced by salt leaching. Then, the scaffolds were loaded postfabrication with different amounts of GYY4137, in order to explore the effects of different concentration of the $\mathrm{H}_{2} \mathrm{~S}$ donor on the properties, the $\mathrm{H}_{2} \mathrm{~S}$ releasing abilities, and the cytotoxicity of the final products.

\section{MATERIALS AND METHODS}

Materials. $\mathrm{H}_{2} \mathrm{~S}$ donor GYY4137 $\left(M_{\mathrm{w}}=376.47 \mathrm{~g} / \mathrm{mol}\right)$ was purchased from Cayman Chemical (Ann Arbor, MI, U.S.A.). GYY4137 was supplied as the morpholinium salt of ( $p$ methoxyphenyl)morpholino-phosphinodithioic acid, a white crystalline solid (Figure 1).

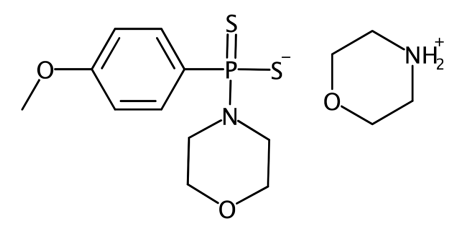

Figure 1. Structural formula of the $\mathrm{H}_{2} \mathrm{~S}$ donor GYY4137.

Anhydrous dimethyl sulfoxide (DMSO), lithium bromide ( $\mathrm{LiBr}$ ), sodium carbonate $\left(\mathrm{Na}_{2} \mathrm{CO}_{3}\right)$, and sodium chloride $(\mathrm{NaCl})$ were purchased from Sigma-Aldrich (Saint Louis, MO, U.S.A.).

Bombyx mori cocoons (purchased from Chul Thai Silk Co., Phetchabun, Thailand) were used as source of SF.

Preparation of SF Aqueous Solution. Silk cocoons were degummed by two consecutive treatments with $\mathrm{Na}_{2} \mathrm{CO}_{3}$ aqueous solutions, at a concentration of 1.1 and $0.4 \mathrm{~g} / \mathrm{L}$, respectively, at $98{ }^{\circ} \mathrm{C}$ for $1.5 \mathrm{~h}$ each time. The fibers obtained were deeply rinsed with deionized (DI) water and then air-dried. Degummed SF was dissolved at a concentration of $20 \% \mathrm{w} / \mathrm{V}$ in $9.3 \mathrm{M}$ aqueous $\mathrm{LiBr}$ at $65{ }^{\circ} \mathrm{C}$ for 4 h. To eliminate $\mathrm{LiBr}$, the solution was dialyzed in a Slide-A-Lyzer Dialysis Cassette with $3.5 \mathrm{kDa}$ MWCO (Thermo Fisher Scientific, Waltham, MA, U.S.A.), against DI water for 3 days, with regular water changes. Finally, SF aqueous solution was filtered to eliminate any solid residue in suspension and the concentration was measured and adjusted to $8 \% \mathrm{w} / \mathrm{V}$.

Preparation of Scaffolds. Porous SF scaffolds were produced by solvent casting and particulate leaching method, as described by Rockwood et al. ${ }^{19}$ Briefly, $14 \mathrm{~g}$ of granular $\mathrm{NaCl}$ (particle size between 425 and $800 \mu \mathrm{m}$ ) were added in a polystyrene Petri dish, and $6.5 \mathrm{~mL}$ of $8 \% \mathrm{w} / \mathrm{V}$ fibroin aqueous solution were poured on the salt $(\mathrm{NaCl}(\mathrm{g})$ to fibroin $(\mathrm{g})$ was 25 to 1$)$. After $48 \mathrm{~h}$ at room temperature, gelation of $\mathrm{SF}$ solution occurred. $\mathrm{NaCl}$ was then removed by washing samples in DI water for 4 days, with regular water changes. Cylindrical-shaped scaffolds of $3 \mathrm{~mm}$ in thickness, 6 $\mathrm{mm}$ in diameter, and $6 \mathrm{mg}$ in weight were obtained using a $6 \mathrm{~mm}$ biopsy punch; afterward, samples were frozen and freeze-dried to remove water. GYY4137 was dissolved in DMSO to prepare three solutions at different concentration $(1.5,7.5$, and $15.0 \mathrm{mg} / \mathrm{mL}$ of GYY4137 in DMSO, respectively). Each scaffold was impregnated with $40 \mu \mathrm{L}$ of GYY4137 solution in DMSO, and GYY4137-loaded scaffolds with $1 \%, 5 \%$ and $10 \%$ content of GYY4137 in weight with respect to the SF weight were prepared. A set of samples where only pure anhydrous DMSO was poured on the scaffolds was also prepared. The scaffolds were then frozen at $-80^{\circ} \mathrm{C}$, and freeze-dried to remove DMSO. The volume of loading solution was chosen on the basis of DMSO uptake by the scaffolds which was determined as equal to $6.9 \pm 1.0$ times the weight of each scaffold.

All scaffolds were sterilized by Cobalt- 60 gamma $(\gamma)$ irradiation in a standard cycle of $25.0 \mathrm{kGy}$ (nominal dose) by Sterigenics Italy (Minerbio, Italy). Facilities and control procedures validated in conformity with the guidelines ISO 9001, ISO 13485, EN ISO 13485, and good manufacturing practices (GMP) were used.

The different types of scaffolds obtained starting from fibroin solution and the sample codes are listed in Figure 2.

Sample Characterization. Scanning Electron Microscopy. For the morphological characterization, SF scaffolds were sputter-coated with a thin platinum/palladium layer (by a Q150T Turbo-Pumped Sputter Coater/Carbon Coater, Quorum Technologies, U.K.), and then observed with a Field Emission Scanning Electron Microscope (FE-SEM, Zeiss Supra 40, Carl Zeiss, Germany), in secondary electron mode. Pore size was calculated with Image-J software $(\mathrm{NIH}$, 


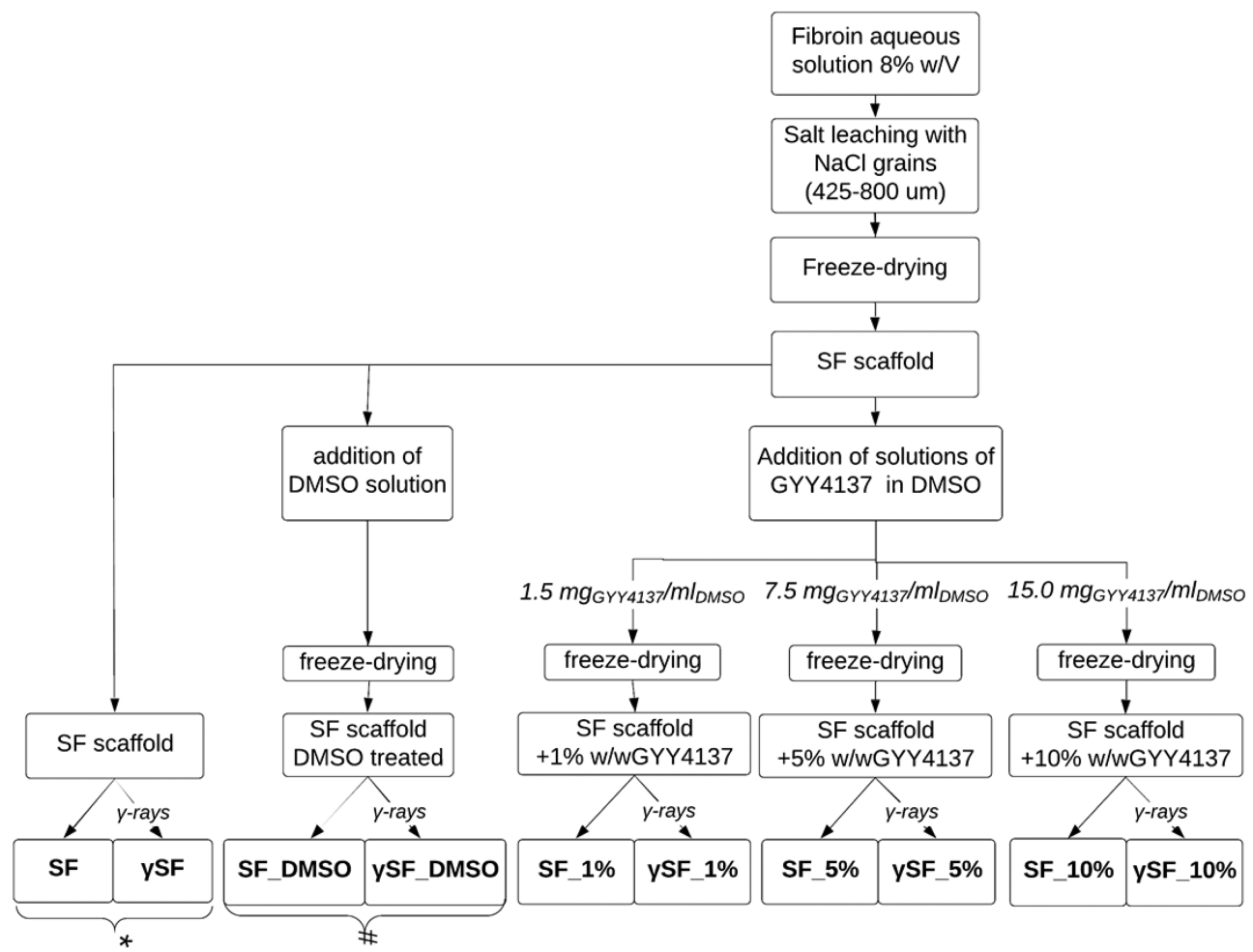

Figure 2. Scheme of the preparation procedure, composition and codes of the scaffolds fabricated. In parallel with GYY4137-loaded scaffolds, also scaffolds treated with DMSO (\#) and untreated fibroin scaffolds $(*)$ were produced as controls.

U.S.A.), measuring around 100 pores for each group. Pore size distribution was evaluated using OriginPro 8 (OriginLab, U.S.A.) software, and expressed as mean \pm standard error of the mean (SEM). Gaussian distribution of pores was assumed.

Fourier Transform Infrared (FT-IR) Spectroscopy. Fourier transform infrared spectroscopy was used to investigate the chemicophysical properties of the materials fabricated. A Spectrum One FT-IR spectrometer (PerkinElmer, Waltham, MA, U.S.A.) working in attenuated total internal reflection (ATR) mode was used to collect the spectra of the different materials. Four scans for each spectrum were registered in the wavenumber range $4000-650 \mathrm{~cm}^{-1}$, with a resolution of $4 \mathrm{~cm}^{-1}$. FTIR spectra peaks were detected by SEARCH Plus Software for PerkinElmer Spectrum One FTIR (PerkinElmer, Waltham, MA, U.S.A.), and assigned to specific vibrations. ${ }^{34}$

To study the influence of the preparation of GYY4137-loaded scaffolds on GYY4137 chemical properties, commercial GYY4137 was solubilized in DMSO at $15 \mathrm{mg} / \mathrm{mL}$, lyophilized and characterized by FT-IR before and after treatment with $\gamma$-irradiation. The samples considered are listed in Table 1.

Table 1. Different Forms of GYY4137 Considered in This Work

\begin{tabular}{ll}
\multicolumn{1}{c}{ material code } & \multicolumn{1}{c}{ details } \\
GYY & commercial GYY4137 \\
$\gamma$ GYY & $\begin{array}{l}\text { commercial GYY4137, } \gamma \text {-irradiated } \\
\text { GYY_exDMSO }\end{array}$ \\
$\gamma$ GYY4137 solubilized in DMSO, freeze-dried \\
$\begin{array}{l}\text { GYY4137 solubilized in DMSO, freeze-dried, } \\
\gamma \text {-irradiated }\end{array}$ \\
\hline
\end{tabular}

GYY4137-loaded scaffolds were analyzed by FT-IR to assess the presence of GYY4137 in the SF matrices, and to determine SF conformation. In particular, SF secondary structures in the scaffolds were determined by analyzing the Amide I region $\left(1705-1610 \mathrm{~cm}^{-1}\right)$ of the correspondent FTIR spectra, by OriginPro 8 (OriginLab, U.S.A.). Amide I regions were selected and smoothed with a ninepoint Savitzky-Golay smoothing filter. Then, Fourier self-deconvolu- tion (FDS tool of OriginPro 8) was applied, using the wavenumber ranges adapted from literature of seven fitting peaks. ${ }^{35,36}$ The seven peaks, assumed to be Gaussian, were assigned to the four different proteins secondary structures considered for SF ( $\beta$-sheet, random coil, $\alpha$-helix and turns), as reported in Table 2.

Table 2. Vibrational Band Assignments for the Amide I IR Region of Fibroin Spectra Adapted from Ref 35

\begin{tabular}{cl} 
wavenumber range $\left(\mathrm{cm}^{-1}\right)$ & band assignment \\
$1616-1621$ & $\beta$-sheet \\
$1622-1637$ & $\beta$-sheet \\
$1638-1655$ & random coil \\
$1656-1662$ & $\alpha$-helix \\
$1663-1670$ & turns \\
$1671-1696$ & turns \\
$1697-1703$ & $\beta$-sheet \\
\hline
\end{tabular}

The content percentage of secondary structures present in the scaffolds was calculated by integrating the area of each deconvoluted peak and then normalizing to the total area of the Amide I spectra region analyzed.

Solid-State Nuclear Magnetic Resonance (NMR) Spectroscopy. NMR analyses were performed on ${ }^{13} \mathrm{C}$ and ${ }^{31} \mathrm{P}$ nuclei. The study of ${ }^{13} \mathrm{C}$ nuclei was used for the characterization of GYY4137, before and after solubilization in DMSO and treatment with $\gamma$-irradiation, and of GYY4137-loaded scaffolds. In particular, since ${ }^{13} \mathrm{C}$ chemical shift is an intrinsic and sensitive parameter for the evaluation of protein conformations, it was used to examine the possible conformational behavior of SF induced by the scaffold preparation processes. Following a profile fitting of $\mathrm{SF}$ alanine ${ }^{13} \mathrm{C} \beta$ peak previously reported, the dominant polymorphic conformation between Silk II ( $\beta$ sheets crystals in amorphous matrix) and Silk I (random coil, turn and $\alpha$-helix structures) adopted by the protein in the scaffolds was calculated. ${ }^{37,38}$ Since GYY4137 molecules contain a phosphorus atom, ${ }^{31} \mathrm{P}$ NMR was used for the selective study of GYY4137 chemical shifts. 
NMR analyses were performed with a Bruker 400WB spectrometer (Bruker Corporation, Billerica, MA, U.S.A.) operating at a proton frequency of $400.13 \mathrm{MHz}$. NMR spectra were acquired with crosspolarization (CP) and single pulse (SP) sequences, under the following conditions: for ${ }^{13} \mathrm{C}$, frequency $100.23 \mathrm{MHz}, \pi / 23.4 \mu \mathrm{s}$, contact time $2 \mathrm{~ms}$, decoupling length $6.7 \mu \mathrm{s}$, recycle delay 5 and $30 \mathrm{~s}$ for $\mathrm{CP}$ and SP respectively, $2 \mathrm{k}$ scans; for ${ }^{31} \mathrm{P}$, frequency $162.49 \mathrm{MHz}$, $\pi / 23.65 \mu$ s, contact time $5 \mathrm{~ms}$, decoupling length $6.7 \mu$ s, recycle delay 5 and $100 \mathrm{~s}$ for for CP and SP respectively, 8 scans (1k scans for loaded sponges). Samples were packed in $4 \mathrm{~mm}$ zirconia rotors, which were spun at $7.5 \mathrm{kHz}$ under air flow. Adamantane $\mathrm{CH} 2$ at $38.5 \mathrm{ppm}$ and ammonium dihydrogen phosphate at $0.81 \mathrm{ppm}$ were used as external secondary references for ${ }^{13} \mathrm{C}$ and ${ }^{31} \mathrm{P}$, respectively.

Differential Scanning Calorimetry (DSC) and Thermogravimetric Analysis (TGA). DSC and TGA techniques were used to investigate the thermal behavior of GYY4137 and the GYY4137-loaded scaffolds. DSC experiments were performed using a DSC20 calorimeter (Mettler-Toledo, Milan, Italy). For each sample, approximately 15 $\mathrm{mg}$ of material were placed in aluminum pans and tested under flushing nitrogen $(100 \mathrm{~mL} / \mathrm{min})$, in the temperature range $30-330$ ${ }^{\circ} \mathrm{C}$, at a heating rate of $10{ }^{\circ} \mathrm{C} / \mathrm{min}$. TGA was conducted in a TA Instruments Q5000 thermobalance, testing about $10 \mathrm{mg}$ of material in freshly cleaned platinum pans, under $\mathrm{N}_{2}$ flow $(10 \mathrm{~mL} / \mathrm{min})$, in the temperature range $30-700{ }^{\circ} \mathrm{C}$, at a heating rate of $10{ }^{\circ} \mathrm{C} / \mathrm{min}$.

Water Uptake Measurement. To measure the water uptake of the scaffolds, the samples were immersed in DI water and placed at $37^{\circ} \mathrm{C}$. Then, an excess of water was removed from the sample surfaces by gently dabbing with paper and the wet weight $\left(W_{\text {wet }}\right)$ was determined. The same procedure was repeated at various time intervals until $W_{\text {wet }}$ was stable. Samples were then dried in oven at $65{ }^{\circ} \mathrm{C}$ overnight and the dry weight $\left(W_{\text {dry }}\right)$ was determined. The water uptake was calculated as $\left(W_{\text {wet }}-W_{\text {dry }}\right) / W_{\text {dry }}$. Values were expressed as mean with $\operatorname{SEM}(n=3$ samples for each group).

Amperometric Detection of $\mathrm{H}_{2} \mathrm{~S}$ Release. $\mathrm{H}_{2} \mathrm{~S}$ release was measured during incubation of the scaffolds in aqueous PBS $0.01 \mathrm{M}$ at $\mathrm{pH}$ 7.4, at room temperature, in the presence of L-cysteine $4 \mathrm{mM}$. Three replicates of each sample were studied. The concentration of hydrogen sulfide in the incubation medium was monitored for $2.5 \mathrm{~h}$, with a sulfide gas amperometric microsensor $\mathrm{H}_{2} \mathrm{~S}-500$ (Unisense, Aarhus N, Denmark), connected to a microsensor multimeter (Unisense, Aarhus N, Denmark) as amplifier for data acquisition. The signal was collected in $\mathrm{mV}$, and converted in concentration units. The $\mathrm{H}_{2} \mathrm{~S}$ microsensor was calibrated with $\mathrm{Na}_{2} \mathrm{~S}^{*} 9 \mathrm{H}_{2} \mathrm{O} \quad 0.01 \mathrm{M}$ dissolved in a $\mathrm{N}_{2}$-flushed solution buffered at $\mathrm{pH} 3.6$, in accordance with manufacturer instructions. ${ }^{39}$

Cell Culture. NIH/3T3 embryonic mouse fibroblasts and hMSCs were used for in vitro studies conducted on fibroin scaffolds with different contents of GYY4137. NIH/3T3 cells (Istituto Zooprofilattico Sperimentale della Lombardia e dell'Emilia Romagna, Italy) were cultured in Dulbecco's Modified Eagle's Medium (DMEM) (EuroClone, Pero, Italy) supplemented with $10 \%$ fetal bovine serum (FBS), $1 \%$ of Antibiotic-Antimycotic 100×, $2 \mathrm{mM}$ L-Glutamine $100 \times$, and $1 \mathrm{mM}$ Sodium Pyruvate 100×. hMSCs (Istituto Ortopedico Rizzoli, Bologna, Italy) were obtained as previously described. ${ }^{8,40}$ hMSCs were isolated from bone marrow aspirate during hipreplacement surgery of 2 posttraumatic patients. The cells were washed twice and suspended in $\alpha$-MEM with $15 \%$ FBS (Lonza, Basel, Switzerland), counted, and plated in flask. After 1 week, the nonadherent cells were removed, and the adherent hMSCs were expanded in vitro. hMSCs were used at passage 3 in culture. Cells of both lines were subcultured as monolayers at $37{ }^{\circ} \mathrm{C}$, in $5 \% \mathrm{CO}_{2}$ atmosphere, and medium was changed every 2-3 days. Cells were detached when they reached $80 \%$ confluence, according to standard protocols, and used for the experiments. In particular, cells were counted and suspended in culture medium. Then, sterile fibroin scaffolds of all the different compositions were placed in 96-well plates and preconditioned for $10 \mathrm{~min}$ with culture medium that was removed before cell seeding. A volume of $50 \mu \mathrm{L}$ of cell suspension containing $5 \times 10^{3}$ cells was deposited on the top of each cylindrical scaffold ( $3 \mathrm{~mm}$ in thickness, $6 \mathrm{~mm}$ in diameter and $6 \mathrm{mg}$ in weight), and 96-well plates were incubated at $37^{\circ} \mathrm{C}$, in $5 \% \mathrm{CO}_{2}$ atmosphere, for $1 \mathrm{~h}$ ("drop confined" cell seeding method). Finally, more culture medium was added to each well containing the scaffolds in order to obtain a total volume of $200 \mu \mathrm{L}$ of medium/well, which could submerge the scaffolds. Seeded cells were maintained at $37^{\circ} \mathrm{C}$, in $5 \%$ $\mathrm{CO}_{2}$ atmosphere for $24 \mathrm{~h}$.

Measurement of In Vitro Cytotoxicity of GYY4137-Loaded Scaffolds. Lactate dehydrogenase (LDH) enzyme released into the medium from cells cultured in the presence of the scaffolds was measured, and used as a biomarker for the evaluation of cellular toxicity and lysis. The potential cytotoxicity effect was measured for silk fibroin scaffolds loaded with different concentrations of GYY4137, untreated fibroin scaffolds, and scaffolds treated with DMSO; the values were then compared with positive and negative controls, respectively, cells seeded on plastic then lysed, and healthy cells seeded on plastic, at a density of $5 \times 10^{3}$ cells/well.

Cells seeded on scaffolds and control wells in the conditions previously described were cultured for $24 \mathrm{~h}$, and then positive control for the LDH assay was prepared by inducing lysis with Triton X-100 surfactant in cells cultured on tissue culture plate. After cell lysis in positive control wells occurred (in around $1 \mathrm{~h}$ ), all media from positive and negative controls, and from scaffold-containing wells were collected, centrifuged to remove cell debris, and transferred into a new plate to be tested. Lactic dehydrogenase-based assay (TOX7, Sigma-Aldrich) was performed according to manufacturer's instructions. Absorbance was measured using a microplate reader (Spark $10 \mathrm{M}$, Tecan Group, Männedorf, Switzerland) at $490 \mathrm{~nm}$, with background absorbance measured at $690 \mathrm{~nm}$. Results were presented as mean with SEM ( $n=5$ and $n=2$, for experiments with 3 T3 and hMSC cells respectively). Statistical analysis was conducted by oneway analysis of variance (ANOVA) using GraphPad Prism version 5.03 (GraphPad software, CA, U.S.A.), and Bonferroni's multiple comparison test was used to evaluate significant differences among the cytotoxicity induced by the different groups of scaffolds. Two sets of samples were considered significantly different when $p<0.05$.

\section{RESULTS}

As previously described, SF porous scaffolds were prepared by processing SF solutions with solvent casting and particulate leaching method, using granular $\mathrm{NaCl}$ with particle size between 425 and $800 \mu \mathrm{m}$. The scaffolds were either left untreated or loaded with different amounts of GYY4137 by using DMSO as vehicle. Finally, freeze-dried scaffolds were $\gamma$ irradiated to obtain sterile products. All sample characterizations were performed before and after the sterilization procedure by $\gamma$-irradiation, which did not induce any changes in the properties of the scaffolds. Thus, only the results collected for $\gamma$-irradiated samples were reported and discussed in this work.

Microstructure and Porosity of Scaffolds. The morphology of the SF scaffolds, untreated and loaded with different amounts of GYY4137, was investigated by scanning electron microscopy. SEM images of Figure $3 \mathrm{~A}$ revealed similar morphology characteristics for all the groups of scaffolds prepared. The scaffolds showed a highly porous sponge-like structure. The round-shaped pores appeared homogeneously distributed and characterized by a high degree of interconnectivity. A bimodal distribution of the pore dimensions could be appreciated (Figure 3B). The larger pores had an average size of $350 \pm 8 \mu \mathrm{m}, 365 \pm 8 \mu \mathrm{m}, 369 \pm 5 \mu \mathrm{m}$, and $378 \pm 4$ $\mu \mathrm{m}$, for $\gamma \mathrm{SF}, \gamma \mathrm{SF} \_1 \%, \gamma \mathrm{SF} 55 \%$, and $\gamma \mathrm{SF} \_10 \%$, respectively. The smaller pores, distributed on the surfaces of the large pores and creating an interconnected network between them, had an average size of $61 \pm 4 \mu \mathrm{m}, 73 \pm 5 \mu \mathrm{m}, 90 \pm 5 \mu \mathrm{m}$, and $95 \pm 7 \mu \mathrm{m}$, for $\gamma \mathrm{SF}, \gamma \mathrm{SF} \_1 \%, \gamma \mathrm{SF} \_5 \%$, and $\gamma \mathrm{SF} \_10 \%$ respectively. Even at high values of magnification, neither 
(A)

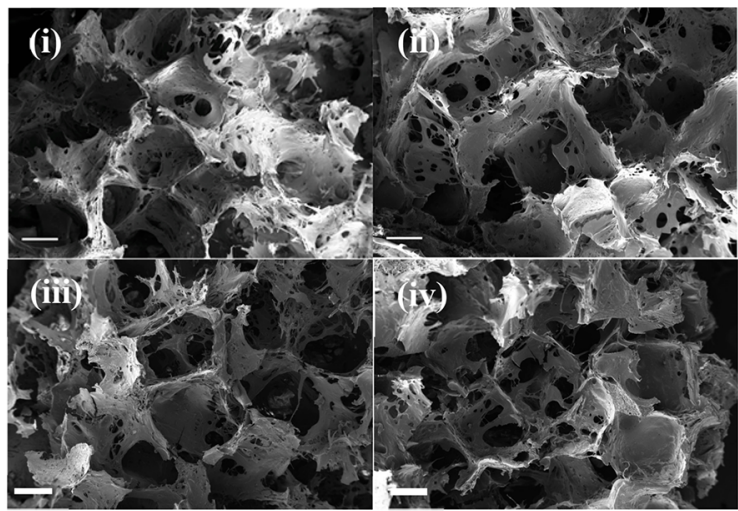

(B)
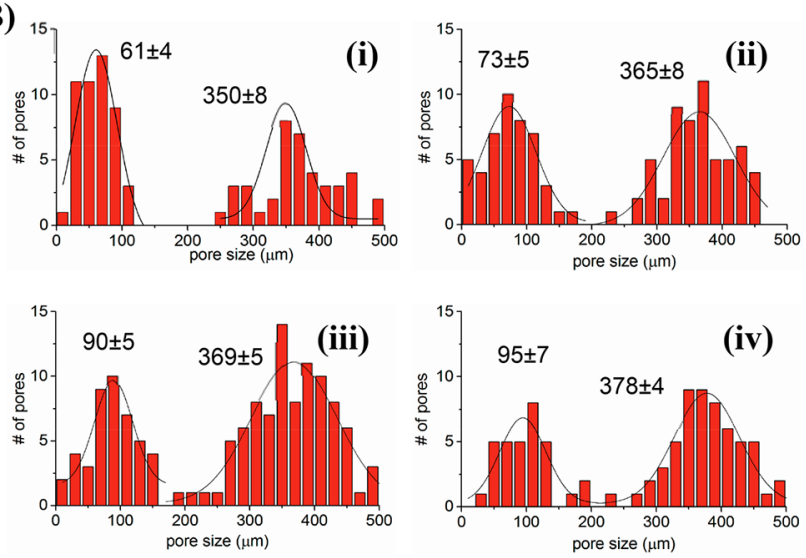

Figure 3. (A) FESEM images of the internal porous structure of dry $\gamma$-irradiated SF scaffolds: (i) $\gamma \mathrm{SF}$, untreated scaffold; (ii) $\gamma \mathrm{SF} \_1 \%$, scaffold containing 1\%GYY4137; (iii) $\gamma$ SF_5\%, scaffold containing 5\% GYY4137; (iv) $\gamma$ SF_10\%, scaffold containing 10\%GYY4137; scale bar $200 \mu \mathrm{m}$. (B) Pore size bimodal distributions measured from FESEM images of samples: (i) $\gamma \mathrm{SF}$; (ii) $\gamma \mathrm{SF} 1 \%$; (iii) $\gamma \mathrm{SF} \quad 5 \%$; (iv) $\gamma \mathrm{SF} \quad 10 \%$, with mean \pm standard error expressed in micrometers calculated for each distribution.

crystals nor agglomerates of GYY4137 were visible on GYY4137-loaded fibroin matrices (images not shown).

FT-IR Spectroscopy. Infrared spectroscopy was used to investigate the chemical structure of GYY4137 and GYY4137 exDMSO, and the composition of GYY4137-loaded scaffolds. In addition, FTIR bands of SF were used to study the protein secondary structure in the scaffolds.

Figure 4 showed that $\gamma \mathrm{GYY}$ and $\gamma \mathrm{GYY}$ exDMSO had similar spectrum profiles. Moreover, their absorption bands were consistent with the infrared spectrum of GYY4137 previously reported in Alexander et al. ${ }^{10}$ The assignments of the bands of samples $\gamma \mathrm{GYY}$ and $\gamma \mathrm{GYY}$ exDMSO to specific groups vibrations are proposed in Table 3 .

The band assigned to $\mathrm{P}-\mathrm{S}$ bond stretch, visible at 650 $\mathrm{cm}^{-1}$, was maintained on both spectra. ${ }^{16}$ However, some changes in peak relative intensities and shape before and after dissolution of GYY4137 in DMSO and lyophilization were clearly visible, especially for peaks at $1593 \mathrm{~cm}^{-1}, 1453 \mathrm{~cm}^{-1}$, $1182 \mathrm{~cm}^{-1}$, around $1028 \mathrm{~cm}^{-1}$, and $935 \mathrm{~cm}^{-1}$. Most of these absorption peaks can be assigned to vibrations of $\mathrm{C}-\mathrm{N}$ and $\mathrm{C}-\mathrm{O}$ bonds present in the structure of the two morpholine groups of GYY4137 molecule.

Figure 4 also reported the FTIR spectra of GYY4137-loaded scaffolds and, for comparison, the spectra of $\gamma \mathrm{SF}$ and $\gamma$ SF_DMSO. Curves of $\gamma \mathrm{SF}$ and $\gamma$ SF_DMSO were both

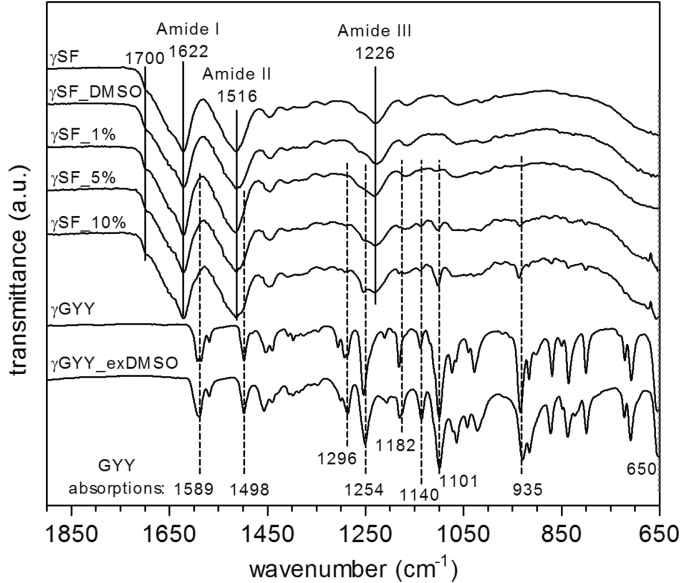

Figure 4. Comparison between the IR spectra of $\gamma$ GYY ( $\gamma$-irradiated GYY4137 reagent) and $\gamma$ GYY exDMSO (GYY4137 solubilized in DMSO and lyophilized), and IR spectra of $\gamma$-irradiated fibroin scaffolds: $\gamma \mathrm{SF}$, untreated; $\gamma \mathrm{SF} \_\mathrm{DMSO}$, treated with DMSO; $\gamma \mathrm{SF} \_1 \%$, containing $1 \%$ of GYY4137; $\gamma \mathrm{SF} 5 \%$, containing 5\% of GYY4137; $\gamma \mathrm{SF} \_10 \%$, containing $10 \%$ of GYY4137. Solid lines indicate absorption bands characteristic of SF; dashed lines indicate peaks of GYY4137 discussed in the text.

characterized by the typical protein backbone absorption bands, i.e. Amide I, II, and III, which are very useful for conformation studies. ${ }^{41,42}$ In particular, Amide I and Amide II bands appeared broad and centered at wavenumbers correlated with a prevalence of $\beta$-sheet secondary structure, respectively, at 1622 and $1516 \mathrm{~cm}^{-1} \cdot 35,38$ Amide I presented a shoulder at $1690 \mathrm{~cm}^{-1}$, suggesting the presence of $\beta$-sheet crystallinity of the antiparallel type. ${ }^{43}$ Amide III band was centered at 1226 $\mathrm{cm}^{-1}$, with a shoulder at $1265 \mathrm{~cm}^{-1}$, confirming that $\beta$-sheet was the main conformation adopted by fibroin in $\gamma$ SF scaffold.

Curves of GYY4137-loaded fibroin scaffolds (i.e., $\gamma \mathrm{SF} \_1 \%$, $\gamma \mathrm{SF}$ 5\%, and $\left.\gamma \mathrm{SF} \_10 \%\right)$ exhibited absorption profiles similar to samples $\gamma$ SF and $\gamma$ SF DMSO for Amide I, II, and III bands. In addition, peaks derived from the presence of GYY4137 were clearly visible only for samples $\gamma \mathrm{SF} \_5 \%$ and $\gamma \mathrm{SF} \_10 \%$ and their intensity increased proportionally with the amount of GYY4137 incorporated in the scaffolds. The curve of $\gamma \mathrm{SF} 5 \%$ presented peaks at 1593 and $1498 \mathrm{~cm}^{-1}, 1296 \mathrm{~cm}^{-1}, \overline{1254}$ $\mathrm{cm}^{-1}, 1182 \mathrm{~cm}^{-1}, 1140 \mathrm{~cm}^{-1}, 1101 \mathrm{~cm}^{-1}, 935 \mathrm{~cm}^{-1}$, and between 835 and $800 \mathrm{~cm}^{-1}$, related to GYY4137 absorptions. $\gamma \mathrm{SF} 10 \%$ spectrum featured similar but more intense absorption frequencies deriving from the presence of GYY4137. However, it was not possible to appreciate if these absorptions were more similar to those detected for $\gamma \mathrm{GYY}$ or for $\gamma \mathrm{GYY}$ exDMSO.

The results of the protein Amide I analysis are reported in Figure 5A and showed similar amounts of secondary structures for all the scaffolds. In particular, the scaffolds displayed similar amounts of $\beta$-sheet. Fibroin had 53\%, 53\%, 56\%, 55\% and 54\% of $\beta$-sheet secondary structure respectively in $\gamma \mathrm{SF}$, $\gamma$ SF_DMSO, $\gamma$ SF_1\%, $\gamma$ SF_5\% and $\gamma$ SF_10\%. The differences between these values were considered not significant. The rest of the protein was mainly organized in random coil and turn structures, with a small amount of $\alpha$-helix. Figure 5B shows an example of an absorbance spectrum of Amide I, deduced after Fourier self-deconvolution with seven peaks, as described previously in this manuscript. The different secondary 
Table 3. Infrared Vibrational Bands and Assignments of Samples $\gamma$ GYY and $\gamma$ GYY_exDMSO (GYY4137 Solubilized and Lyophilized in DMSO)

\begin{tabular}{|c|c|c|}
\hline$\gamma \mathrm{GYY} \nu\left(\mathrm{cm}^{-1}\right)$ & $\gamma \mathrm{GYY} \_$exDMSO $\nu\left(\mathrm{cm}^{-1}\right)$ & band assignment \\
\hline $1593,1586,1569,1498$ & $1589,1569,1498$ & aromatic $\mathrm{C}=\mathrm{C}$ stretch $(1600-1475)$ and $\mathrm{N}-\mathrm{H}$ bend above 1550 \\
\hline 1453,1440 & 1457 & alkanes $\mathrm{C}-\mathrm{H}$ deformation \\
\hline 1408,1397 & 1398 & $\mathrm{CH}_{3}$ bend \\
\hline 1306,1293 & 1286 & $\mathrm{C}-\mathrm{N}$ vibrations \\
\hline 1254 & 1251 & aromatic $\mathrm{C}-\mathrm{O}$ stretch (pheyl-O-alkyl) \\
\hline 1181,1138 & 1180,1136 & $\mathrm{C}-\mathrm{N}$ vibrations and $\mathrm{C}-\mathrm{O}-\mathrm{C}$ stretch \\
\hline 1099 & 1099 & $\mathrm{C}-\mathrm{O}$ and/or $\mathrm{C}-\mathrm{N}$ stretch \\
\hline 1073,1040 & 1064,1042 & n.a. \\
\hline 1028 & 1022 & phenyl-O-alkyl \\
\hline $934,916,902$ & 929,915 & n.a. \\
\hline 869 & 872 & para substituted aromatic ring $\mathrm{C}-\mathrm{H}$ deformation \\
\hline 836 & 837 & benzene ring $\mathrm{C}-\mathrm{H}$ deformation \\
\hline 800 & 799 & $=\mathrm{C}-\mathrm{H}$ aromatics or $\mathrm{N}-\mathrm{H}$ (out-of-plane bend) \\
\hline 721,708 & 722,709 & benzene ring $\mathrm{C}-\mathrm{H}$ deformation \\
\hline 650 & 650 & $\mathrm{P}=\mathrm{S}$ stretch \\
\hline
\end{tabular}
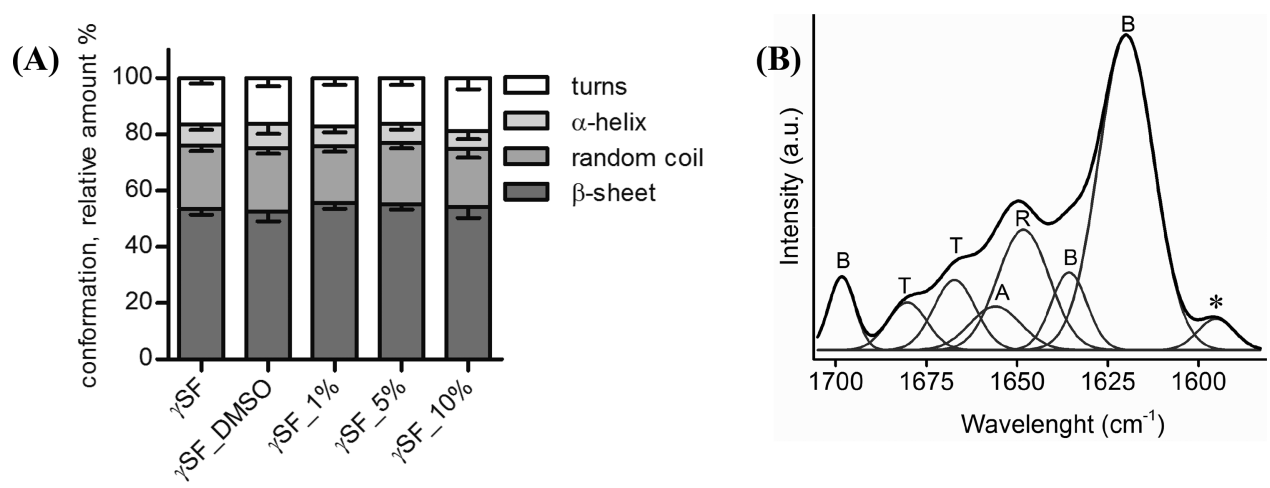

Figure 5. (A) Percentages of the main four different secondary structure ( $\beta$-sheet, random coil, $\alpha$-helix, turns) contributing to fibroin Amide I band. Samples are $\gamma$ SF, untreated scaffold; $\gamma$ SF_1\%, scaffold containing $1 \%$ of GYY4137; $\gamma$ SF_5\%, scaffold containing 5\% of GYY4137; $\gamma$ SF_10\%, scaffold containing $10 \%$ of GYY4137. Mean with SD, $n=3$. (B) Example of an absorbance spectrum of Amide I, deduced after Fourier selfdeconvolution with seven peaks. B is $\beta$-sheet, T is turns, $\mathrm{A}$ is $\alpha$-helix and $\mathrm{R}$ is random coil. Peak marked with * is assigned to tyrosine side chains, not considered in the quantification of the secondary structure.

structure contributions are highlighted with $\mathrm{B}$ for $\beta$-sheet, $\mathrm{T}$ for turns, A for $\alpha$-helix, and R for random coil.

NMR Analysis. The ${ }^{13} \mathrm{C}$ CPMAS NMR spectra of relevant samples are shown in Figure 6.

Sharp signals and two broad peaks characterized the spectrum profile of $\gamma \mathrm{GYY}$ (assignments based on GYY4137 labeled structure in Figure 6 and reported in Table 4). After dissolution of GYY4137 in DMSO and lyophilization, in the ${ }^{13} \mathrm{C}$ spectrum the sharpness of the peaks increased, suggesting improved crystallinity. However, the peaks did not show any shift in position, thus confirming that the dissolution in DMSO did not substantially alter the molecular structure.

The ${ }^{13} \mathrm{C}$ CPMAS NMR spectra of samples $\gamma \mathrm{SF}$ and $\gamma \mathrm{SF} \_10 \%$ were both dominated by the signals belonging to the amino acid main sequence AGS(Y)GAG in SF. ${ }^{38,44}$ Unfortunately, the intense $S F$ resonances hindered the possibility of observing the weak GYY4137 peaks in the spectrum of $10 \%$ GYY4137-loaded scaffold. Only the small peak at $163 \mathrm{ppm}$, which was attributed to C12, was a proof of the presence of adsorbed GYY4137. Comparing the fibroin signals in the two samples, small differences could be appreciated in the case of $\mathrm{Ala} / \mathrm{Gly} \mathrm{C}=\mathrm{O}$ peak centered at $172 \mathrm{ppm}$, and $\mathrm{Ala} \mathrm{CH}_{3}$ signal $(\mathrm{C} \beta)$ centered at $18 \mathrm{ppm}$. Moreover, the appearance of a high-field shoulder on the Gly
$\mathrm{CH}_{2}$ resonance $(\mathrm{C} \alpha)$ at $42 \mathrm{ppm}$ could be observed. According to previous reports that pointed out the high sensitivity of SF secondary structure to processing treatments, the profile fitting procedure was applied to the Ala $\mathrm{C} \beta$ peak of $\gamma \mathrm{SF}, \gamma \mathrm{SF}$ DMSO and $\gamma \mathrm{SF} \_10 \%$ spectra, in order to evaluate the percentage of the possible SF conformations. ${ }^{38}$ The fibroin sponge used in the present work presented $61 \%$ of Silk II conformation, which increased up to $65 \%$ in $\gamma \mathrm{SF} \_\mathrm{DMSO}$ and reached $74 \%$ in the $\gamma$ SF_10\%.

In order to better characterize the features of GYY4137 in the different samples, the ${ }^{31} \mathrm{P}$ CPMAS NMR spectra were recorded (Figure 7). Since fibroin does not contain any phosphorus atoms, it was possible to selectively characterize the $\mathrm{H}_{2} \mathrm{~S}$ donor inside the loaded scaffolds, and compare the results with the characterization conducted on $\gamma \mathrm{GYY}$.

The ${ }^{31} \mathrm{P}$ CPMAS NMR spectrum of $\gamma \mathrm{GYY}$ was characterized by a single sharp peak at $90.5 \mathrm{ppm}$. The recrystallization after DMSO ( $\gamma$ GYY_exDMSO) produced a moderately asymmetric and enlarged resonance at the same position. The spectrum of sample $\gamma \mathrm{SF} \_1 \%$ is not shown, since the peak is beyond the sensitivity limits. The adsorption of 5 and 10\% GYY4137 on SF scaffolds $\left(\gamma \mathrm{SF} \_5 \%\right.$ and $\left.\gamma \mathrm{SF} \_10 \%\right)$ did not affect the $\mathrm{H}_{2} \mathrm{~S}$ donor structure and the peak intensity was in agreement with the different nominal GYY4137 loadings. 

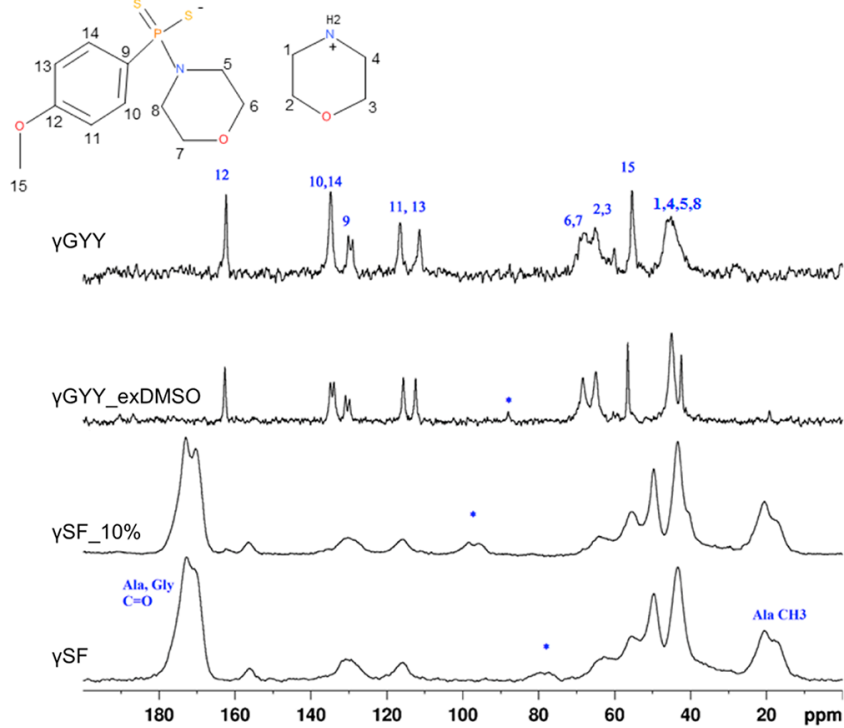

Figure 6. ${ }^{13} \mathrm{C}$ CPMAS NMR spectra of $\gamma$ SF (untreated scaffold), $\gamma \mathrm{SF} \_10 \%$ (containing $10 \%$ of GYY4137), $\gamma \mathrm{GYY}$ ( $\gamma$-irradiated GYY4137 reagent), $\gamma$ GYY_exDMSO (GYY4137 solubilized and lyophilized in DMSO), and GYY4137 molecular structure with C atoms numbering scheme. Spinning sidebands are marked with *.

Table 4. ${ }^{13} \mathrm{C}$ NMR Chemical Shifts of $\gamma \mathrm{GYY}$ and Assignments ${ }^{10}$

\begin{tabular}{|c|c|c|}
\hline \multicolumn{3}{|c|}{$\gamma \mathrm{GYY}$} \\
\hline$\delta(\mathrm{ppm})$ & functional group & C labeling \\
\hline 45.2 & $\mathrm{~N}\left(\mathrm{CH}_{2}\right)_{2}$ morpholinium & 1,4 \\
\hline 45.2 & $\mathrm{~N}\left(\mathrm{CH}_{2}\right)_{2}$ morpholinium attached to $\mathrm{P}$ & 5,8 \\
\hline 55.5 & $\mathrm{OCH}_{3}$ & 15 \\
\hline 65.0 & $\mathrm{O}\left(\mathrm{CH}_{2}\right)_{2}$ morpholinium & 2,3 \\
\hline 68.3 & $\mathrm{O}\left(\mathrm{CH}_{2}\right)_{2}$ morpholinium attached to $\mathrm{P}$ & 6,7 \\
\hline $111.4 / 116.6$ & $\operatorname{arylCH} o$ - to $\mathrm{OMe}$ & 11,13 \\
\hline $129.2 / 130.2$ & arylC-P & 9 \\
\hline 134.9 & arylCH $o$ - to $\mathrm{P}$ & 10,14 \\
\hline 162.7 & arylC-OMe & 12 \\
\hline
\end{tabular}

Thermal Analyses: DSC and TGA. The thermal behavior of GYY4137 and GYY4137-loaded scaffolds was studied by DSC and TGA. Figure 8A reports DSC thermogram of $\gamma \mathrm{GYY}$ powders, showing two endothermic peaks, centered at $\mathrm{T}^{\mathrm{I}}=$ $123{ }^{\circ} \mathrm{C}(\Delta H=54 \mathrm{~J} / \mathrm{g})$, and $\mathrm{T}^{\mathrm{II}}=169{ }^{\circ} \mathrm{C}(\Delta H=63 \mathrm{~J} / \mathrm{g})$, related respectively to the decomposition of morpholinium and the melting of ( $p$-methoxyphenyl)morpholino-phosphinodithioate. $^{10,11}$

Figure $8 \mathrm{~B}$ showed the thermograms of GYY4137-loaded scaffolds compared to $\gamma \mathrm{SF}$. All the scaffolds were characterized by a wide endothermic peak centered around $95{ }^{\circ} \mathrm{C}\left(T_{\mathrm{e}}\right)$, related to the loss of absorbed water, and a sharp endothermic peak centered at higher temperatures, around $288{ }^{\circ} \mathrm{C}\left(T_{\mathrm{d}}\right)$, due to the thermal degradation of the protein. ${ }^{38,45-47}$ In particular, degradation of $\gamma$ SF scaffold occurred approximately at $293{ }^{\circ} \mathrm{C}(\Delta H=168 \mathrm{~J} / \mathrm{g})$, with a sharp endothermic peak. GYY4137-loaded scaffolds showed wider degradation peaks with a shift over lower temperatures and lower values of the associated enthalpy. These differences became more evident increasing the amount of loaded GYY4137 from sample $\gamma \mathrm{SF} \_1 \%\left(T_{\mathrm{d}}=290{ }^{\circ} \mathrm{C}, \Delta H=150 \mathrm{~J} / \mathrm{g}\right)$, to $\gamma \mathrm{SF} \_5 \%\left(T_{\mathrm{d}}=289\right.$

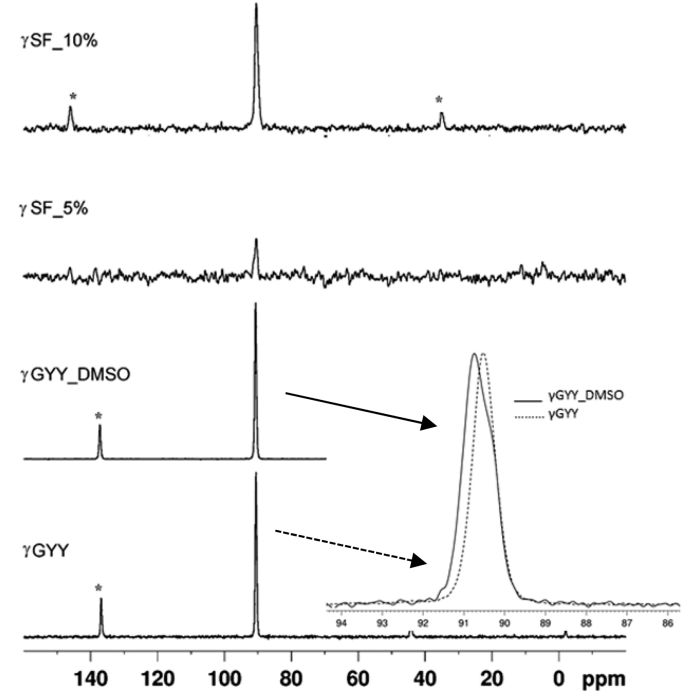

Figure 7. ${ }^{31} \mathrm{P}$ CPMAS NMR spectra of $\gamma$ GYY ( $\gamma$-irradiated GYY4137 reagent), $\gamma$ GYY exDMSO (GYY4137 solubilized and lyophilized in DMSO), $\gamma$ SF_5\% (containing 5\% of GYY4137), $\gamma$ SF_10\% (containing $10 \%$ of GYY4137). Spinning sidebands are marked with *. The inset shows the profiles of the ${ }^{31} \mathrm{P}$ peaks at $90.5 \mathrm{ppm}$ of $\gamma \mathrm{GYY}$ and $\gamma \mathrm{GYY}$ _exDMSO.
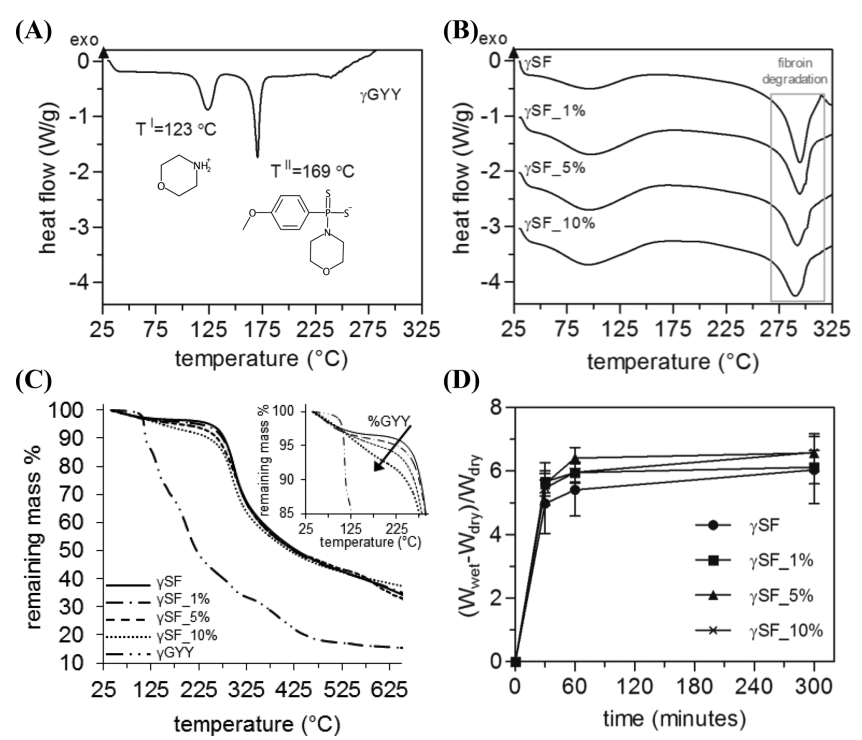

Figure 8. DSC curve obtained for (A) $\gamma$-irradiated GYY4137 and for (B) $\gamma$-irradiated SF scaffolds. (C) TGA analyses of the different SF scaffolds and of $\gamma \mathrm{GYY}$; the inset highlights mass losses in the scaffolds in the temperature range of GYY4137 degradation. GYY4137 content increases in the direction of the arrow. (D) Water uptake curves of the scaffolds incubated in water at $37{ }^{\circ} \mathrm{C}$ (mean with SEM, $n=3$ ). Samples are $\gamma \mathrm{SF}$, untreated fibroin scaffold; $\gamma \mathrm{SF} \_1 \%$, scaffold with $1 \%$ of GYY4137; $\gamma$ SF_5\%, scaffold with 5\% of GYY4137; $\gamma$ SF_10\%, scaffold with $10 \%$ of GYY4137; $\gamma \mathrm{GYY}, \gamma$-irradiated GYY4137 reagent.

$\left.{ }^{\circ} \mathrm{C}, \Delta H=127 \mathrm{~J} / \mathrm{g}\right)$ and $\gamma \mathrm{SF} \_10 \%\left(T_{\mathrm{d}}=283{ }^{\circ} \mathrm{C}, \Delta H=136 \mathrm{~J} /\right.$ g).

Interestingly, thermal transitions related to GYY4137 were not visible on the thermograms of scaffolds $\gamma \mathrm{SF} \_1 \%, \gamma \mathrm{SF} \_5 \%$, and $\gamma \mathrm{SF} \quad 10 \%$.

TGA gave the mass losses occurred in $\gamma$ GYY powders and in GYY4137-loaded scaffolds during heating from room temperature up to $700{ }^{\circ} \mathrm{C}$. As shown in Figure $8 \mathrm{C}$, the most relevant mass loss in $\gamma \mathrm{GYY}$ powders (around $60 \%$ of the initial weight 
of the sample) occurred between 150 and $300{ }^{\circ} \mathrm{C}$. In the same temperature range, a visible mass loss could be monitored for scaffolds loaded with GYY4137, but not for $\gamma \mathrm{SF}$ : the mass loss $\%$ resulted proportional to the amount of GYY4137 loaded into the SF sponges. Above $300{ }^{\circ} \mathrm{C}$ (i.e., after the beginning of fibroin degradation), most of the weight was lost from all the scaffolds, leaving a residue of around $30 \%$ at $700{ }^{\circ} \mathrm{C}$.

Water Uptake Evaluation. The curves of the water uptake of the scaffolds were reported in Figure $8 \mathrm{D}$ and showed comparable profiles for the different samples. The process of water uptaking was completed after $60 \mathrm{~min}$ of incubation. After $300 \mathrm{~min}$, the weight of wet scaffolds was stable and was used to calculate the water uptake as $\left(W_{\text {wet }}-W_{\text {dry }}\right) / W_{\text {dry }}$. Water uptake measured $6.0 \pm 1.8$ for scaffold $\gamma \mathrm{SF}, 7.8 \pm 2.0$ for $\gamma \mathrm{SF} 1 \%, 6.1 \pm 0.9$ for $\gamma \mathrm{SF} 5 \%$, and $6.6 \pm 1.0$ for $\gamma \mathrm{SF} 10 \%$.

Release of $\mathrm{H}_{2} \mathrm{~S}$ from GYY4137-Loaded Scaffolds. Amperometry was used for the continuous record of $\mathrm{H}_{2} \mathrm{~S}$ in the incubation media of GYY4137-loaded scaffolds. The $\mathrm{H}_{2} \mathrm{~S}$ microsensor measured the concentration of the undissociated species indicated as $\mathrm{H}_{2} \mathrm{~S}$ in the equilibrium: $\mathrm{H}_{2} \mathrm{~S} \rightleftarrows \mathrm{HS}^{-} \rightleftarrows$ $\mathrm{S}^{2-}$, with $\mathrm{p} K_{\mathrm{a} 1}=6.9$ and $\mathrm{p} K_{\mathrm{a} 2}>11$. It can be calculated that, at $\mathrm{pH} 7.4$, the concentration of $\mathrm{H}_{2} \mathrm{~S}$ is approximately $30 \%$ of the total dissolved sulfide (i.e., $\mathrm{H}_{2} \mathrm{~S}+\mathrm{HS}^{-}+\mathrm{S}^{2-}$ ). ${ }^{48-50}$

Measurements of the concentration of $\mathrm{H}_{2} \mathrm{~S}$ were collected in continuum for $2.5 \mathrm{~h}$ in the incubation media of GYY4137loaded scaffolds and compared with the results obtained for $\gamma \mathrm{SF}$ and $\gamma \mathrm{SF} \_\mathrm{DMSO}$, which did not release $\mathrm{H}_{2} \mathrm{~S}$. Figure 9A
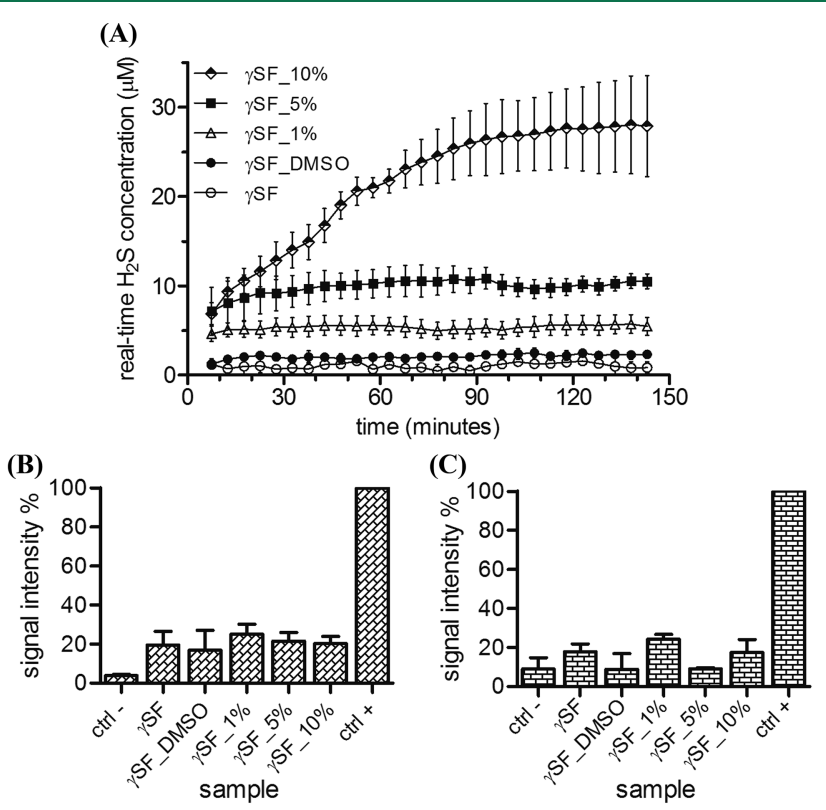

Figure 9. (A) Release of $\mathrm{H}_{2} \mathrm{~S}$ monitored by $\mathrm{H}_{2} \mathrm{~S}$-selective microelectrode for SF scaffolds incubated in PBS pH 7.4 with L-cysteine 4 $\mathrm{mM}$, at room temperature (mean with SEM, $n=4$ ); error bars are not visible when lying within dimensions of symbols. Cytotoxicity of the different groups of scaffolds ( $\gamma \mathrm{SF} \_$DMSO, treated with DMSO; $\gamma \mathrm{SF} 1 \%$, containing $1 \%$ of GYY 4137 ; $\gamma \mathrm{SF} 5 \%$, containing $5 \%$ of GYY $4137 ; \gamma$ SF_10\%, containing 10\% of GYY4137) on (B) 3T3 cells and on (C) hMSCs, expressed as signal intensity \%, proportional to $\mathrm{LDH}$ released in the supernatants, respect to ctrl+. Cells cultured on plastic were used as negative control, while cells treated with $0.05 \%$ Triton X-100 surfactant were used as positive control $(100 \%$ of LDH release). The values are expressed as mean with SEM ( $n=5$ for 3T3 and $n=2$ for hMSC). showed the curves of $\mathrm{H}_{2} \mathrm{~S}$ generation in solution during time. All the GYY4137-loaded fibroin sponges induced a sustained release of $\mathrm{H}_{2} \mathrm{~S}$, but the concentration levels reached at plateau gradually increased with the GYY4137 content of the scaffolds. $\gamma \mathrm{SF} 1 \%$ generated a maximum concentration of $6.5 \mu \mathrm{M}$ of $\mathrm{H}_{2} \mathrm{~S}$ during the $2.5 \mathrm{~h}$ of the experiment. $\mathrm{H}_{2} \mathrm{~S}$ concentration profile for $\gamma \mathrm{SF} \_5 \%$ was similar, but reached higher values at the plateau, settling at $9 \mu \mathrm{M}$. Finally, $\gamma \mathrm{SF} \_10 \%$ generated the highest concentration of $\mathrm{H}_{2} \mathrm{~S}$ in solution: the $\mathrm{H}_{2} \mathrm{~S}$ curve increased over the first $100 \mathrm{~min}$ of incubation and then reached plateau at a concentration of around $31 \mu \mathrm{M}$.

In Vitro Experiments: Cytotoxicity of GYY4137Loaded Scaffolds. In two parallel experiments, 3T3 murine fibroblasts and hMSCs were cultured in the presence of the scaffolds of all the different compositions, for $24 \mathrm{~h}$. The amount of $\mathrm{LDH}$ released in culture media from the cells was measured and used to determine the potential toxic effects of the scaffolds, by comparison with the results obtained for positive and negative control samples. The results of the $\mathrm{LDH}$ assays are shown in Figure 9B,C. For both cell types, the mean value of $\%$ of cytotoxicity calculated for $\gamma \mathrm{SF}$ scaffolds was around 19\%, confirming that salt-leached fibroin matrices ensured the viability of seeded cells, as previously demonstrated. $^{31}$ Similarly, also the cytotoxicity induced by $\gamma$ SF_DMSO, that is, the scaffold contacted with DMSO but not containing GYY4137, was limited. The amount of LDH released by 3T3 cells did not increase for GYY4137-loaded scaffolds, which induced only between $20 \%$ and $25 \%$ of cytotoxicity (i.e., very close to $\gamma \mathrm{SF}$ ). Likewise, GYY4137loaded scaffolds resulted also minimally cytotoxic for hMSCs, with some variability between samples that showed $24 \%, 9 \%$, and $17 \%$ of released $\mathrm{LDH}$, respectively for $\gamma \mathrm{SF} \_1 \%, \gamma \mathrm{SF} \_5 \%$, and $\gamma \mathrm{SF} \_10 \%$.

\section{DISCUSSION}

The current study was intended to the preparation of a novel $3 \mathrm{D}$ system to achieve localized and sustained release of $\mathrm{H}_{2} \mathrm{~S}$ for a future application in bone tissue engineering. A SF matrix, already shown to promote bone cells development, ${ }^{51}$ was combined with GYY4137, one of the most appreciated donors of $\mathrm{H}_{2} \mathrm{~S}$. In fact, GYY4137 is not toxic and is capable of releasing $\mathrm{H}_{2} \mathrm{~S}$ "slowly", compared with conventional donors (e.g., NaHS), over extended periods of time, both in vitro and in vivo. ${ }^{11}$ When GYY4137 is put in contact with an aqueous environment, the $\mathrm{P}=\mathrm{S}$ bonds start to decompose by hydrolysis, and $\mathrm{H}_{2} \mathrm{~S}$ is generated. Thus, in previous experiments, GYY4137 formulations dissolved in aqueous solution needed to be administered fresh, immediately after the preparation. In this context, the GYY4137-loaded SF scaffolds described in this work represent a novel approach for the administration of GYY4137. Anhydrous DMSO was chosen as solvent and vehicle for the loading of GYY4137 into the sponges because DMSO allowed the preparation of solutions where GYY4137 did not decompose, thus preventing early release of $\mathrm{H}_{2} \mathrm{~S}$ from GYY4137, as proved by spectroscopic analyses. Moreover, after the loading process, it could be completely removed from the scaffolds by freeze-drying. ${ }^{52}$ Dissolution in DMSO and removal of the solvent ( $\gamma \mathrm{GYY}$ _exDMSO), performed on GYY4137 in order to mimic the loading conditions and study their potential effects, induced only slight modifications in GYY4137 crystal structure, with no chemical changes. We hypothesized that GYY4137 crystals, after DMSO, reformed in a new structure 
containing the morpholinium cation in a different arrangement, which caused a diversification of the signals related to morpholine energetic transitions. In fact, both on IR and NMR spectra, some absorption bands assigned to morpholine appeared sharper and better resolved after recrystallization from DMSO. On the other hand, all peaks were maintained on infrared spectra of $\gamma \mathrm{GYY}$ _exDMSO, and phosphorus signal was in the same position at $90.5 \mathrm{ppm}$ on ${ }^{31} \mathrm{P}$ NMR spectra. Similarly, the incorporation of GYY4137 into SF scaffolds did not affect the $\mathrm{H}_{2} \mathrm{~S}$ donor chemical structure: the characteristic bands of GYY4137, when visible, were maintained in the same positions on scaffolds infrared curves, and phosphorus peak on ${ }^{31} \mathrm{P}$ NMR spectra only changed intensity, in agreement with the GYY4137\% of loading.

The morphology and, particularly, the porosity are fundamental features of a scaffold for bone tissue engineering applications. $^{28}$ Porous matrices made of SF were already proposed as scaffolds to culture and grow bone cells in vitro and for guiding new bone tissue formation in vivo. Pores with suitable dimensions (more than $300 \mu \mathrm{m}$ ) and distribution are needed, because they allow cell migration and proliferation, as well as vascularization. ${ }^{26}$ The microstructure of the different SF sponges produced was investigated by FE-SEM imaging, and we could assess that the loading process with the $\mathrm{H}_{2} \mathrm{~S}$ donor preserved the original morphology. The absence of visible GYY4137 agglomerates indicated that a fine dispersion of small GYY4137 crystals was obtained inside the SF scaffolds. A highly interconnected porosity with randomly distributed pores was present in all the scaffolds, with no substantial differences between $\gamma \mathrm{SF}$ and differently loaded sponges. Salt leaching process left a porosity with large and small pores, with dimensions (up to $500 \mu \mathrm{m}$ ) indicated as appropriate for the formation of bone tissue within the scaffold. Pores were smaller than $\mathrm{NaCl}$ grains used because of the partial dissolution of the salt occurred during the addition of the SF solution.

In terms of conformation adopted by fibroin in the scaffolds, infrared spectra showed the positions of the typical protein absorption bands, Amide I, Amide II, and Amide III, which indicated a prevalent $\beta$-sheet secondary structure in all the scaffolds, induced by the use of $\mathrm{NaCl}$ during the salt leaching process. $^{53,54}$ In fact, salt-leached SF scaffolds were stable and did not need any further treatment to be insoluble in water.

The importance to take in account the influence of all the fabrication processing steps on the structure of SF-based materials is well-established. ${ }^{38}$ Thus, to investigate possible changes related to the GYY4137-loading process in SF structure and scaffold crystallinity, an analysis of Amide I infrared absorption band was conducted. In particular, the four protein secondary structures considered for fibroin were $\beta$ sheet, random coil, $\alpha$-helix, and turns. The results, shown in Figure 5 for samples $\gamma \mathrm{SF}, \gamma \mathrm{SF} \_\mathrm{DMSO}, \gamma \mathrm{SF} \_1 \%, \gamma \mathrm{SF} \_5 \%$, and $\gamma \mathrm{SF} \_10 \%$, indicated that all the scaffolds contained comparable relative amount of secondary structure of the $\beta$-sheet type. This resulted in the same levels of crystallinity between the SF matrices, thus proving that the highly ordered secondary conformation is stable upon addition of GYY4137. ${ }^{38,55}$ The profile fitting conducted on the NMR C $\beta$ Ala peak of SF was used to evaluate the $\%$ of Silk II conformation, comprising $\beta$ sheet crystals and so-called $\beta$-sheet-like structures in an amorphous matrix, in the scaffolds. The result was that manipulation (such as the addition of GYY4137 in $\gamma \mathrm{SF} 10 \%$ ) or aging (data not shown) of SF induced a slight increase of the Silk II component. A similar effect for SF materials was already monitored before through the study of the NMR $\mathrm{C} \beta$ Ala peak. ${ }^{56}$

DSC analyses indicated that a difference in the SF scaffolds treatment and composition contributed to their thermal behavior during heating. For GYY4137-loaded scaffolds, the degradation peaks were at lower temperatures compared to the $\gamma \mathrm{SF}$. These effects were presumably related to the presence of GYY4137 decomposing before the temperature of SF degradation. We hypothesize that the environment generated locally and diffusely in the SF matrix by the thermal energy exchanges derived from the melting of GYY4137 induced an anticipated degradation of the scaffolds in their entirety. TGA curves, confirmed that evidence: a mass loss could actually be detected in the temperature range $225 \div 325{ }^{\circ} \mathrm{C}$ for $\gamma \mathrm{GYY}$ and for the GYY4137-loaded scaffolds, but not for $\gamma \mathrm{SF}$.

The retention of the $\mathrm{H}_{2} \mathrm{~S}$ releasing abilities of GYY4137 after the loading into the SF scaffolds was a critical point of this work. Since different amounts of GYY4137 were used, we expected to detect quantities of $\mathrm{H}_{2} \mathrm{~S}$ released in solution upon incubation of the scaffolds proportional to the initial concentrations of GYY4137 w/w\% in SF. To assess this point, GYY4137-loaded scaffolds were incubated and $\mathrm{H}_{2} \mathrm{~S}$ concentration in the media was monitored in continuum, until release curves reached the steady state (i.e., the condition of dynamic equilibrium with constant $\mathrm{H}_{2} \mathrm{~S}$ concentration monitored in solution). The incubation media contained Lcysteine, as Martelli et al. showed that GYY4137 releases $\mathrm{H}_{2} \mathrm{~S}$ in a L-cysteine-dependent mechanism, and endogenous organic thiols like this amino acid are always present in biological environments. ${ }^{13}$ In previous studies, the kinetic of $\mathrm{H}_{2} \mathrm{~S}$ generation process was described, and it was assessed that solutions of GYY4137 $1 \mathrm{mmol} / \mathrm{L}$ in PBS at $\mathrm{pH} 7.4$ generated a peak in $\mathrm{H}_{2} \mathrm{~S}$ concentration in the first $20 \mathrm{~min}$, which then decreased. ${ }^{11,13}$ Moreover, the steady state of $\mathrm{H}_{2} \mathrm{~S}$ release curves was reported to depend on the combination of different processes: not only the concentration of the $\mathrm{H}_{2} \mathrm{~S}$ source but also volatilization and oxidation of $\mathrm{H}_{2} \mathrm{~S}$ dissolved in solution, occurring in parallel at any time. ${ }^{57}$ In this work, we could assess that the incorporation of GYY4137 in the SF matrix influenced the process of $\mathrm{H}_{2} \mathrm{~S}$ generation in solution: the curves of realtime $\mathrm{H}_{2} \mathrm{~S}$ concentration increased gradually, without evident peaks ascribable to burst release phenomena. Differences between the $\mathrm{H}_{2} \mathrm{~S}$ release curves related to $\gamma \mathrm{SF} \_1 \%, \gamma \mathrm{SF} \_5 \%$, $\gamma \mathrm{SF} \_10 \%$ were evidenced: the steady state was reached at higher $\mathrm{H}_{2} \mathrm{~S}$ concentrations increasing the GYY4137\% of loading. The time required to reach the concentration of the plateau was approximately the same for all samples, indicating that the release process occurred at similar rates from all the scaffolds.

The content of GYY4137 in the scaffolds did not have an impact on the viability of the tested cells. To assess this, cells were seeded on the top of the different scaffolds and cultured for $24 \mathrm{~h}$. In this period of time, cells experienced the contact with the upper surface of the scaffolds, and some cells presumably penetrated the scaffolds thanks to the porosity. Moreover, as discussed above on the basis of the curves of realtime $\mathrm{H}_{2} \mathrm{~S}$ concentration, $\mathrm{H}_{2} \mathrm{~S}$ formed and diffused in cell culture medium during the incubation. For both $3 \mathrm{~T} 3$ cells and hMSCs, the progenitors of mature osteoblasts, no significant increase in the cytotoxicity could be detected in cell seeded scaffolds, compared to the negative control. This suggested that the materials tested in the experiment, particularly the different amounts of GYY4137 loaded into the fibroin matrices 
and the consequent released $\mathrm{H}_{2} \mathrm{~S}$, did not exert any toxic effect on the cell lines, independently from their phenotype.

\section{CONCLUSIONS}

In the current study, we provide a proof-of-concept evidence for a novel device based on a long-lasting $\mathrm{H}_{2} \mathrm{~S}$ release in the tissue microenvironment, targeting applications in tissue engineering of the musculoskeletal system. To pursue this aim, a scaffold-based system suitable for bone was chosen in combination with GYY4137, a donor of $\mathrm{H}_{2} \mathrm{~S}$ and potential novel modulator of bone cells functions.

A novel process was designed to incorporate the $\mathrm{H}_{2} \mathrm{~S}$ donor GYY4137 into prefabricated SF porous scaffolds produced by salt leaching method. GYY4137 was incorporated into the scaffolds at different concentrations that were chosen for their capacity to generate specific levels of $\mathrm{H}_{2} \mathrm{~S}$ in solution upon hydrolysis. $^{7,8}$

In summary, we demonstrated that GYY4137 could be quantitatively incorporated into SF porous matrices, without impairing the original chemico-physical properties of the scaffolds constituents. GYY4137-loaded SF sponges maintained the morphology and protein conformation exhibited by $\gamma \mathrm{SF}$ scaffold, and the $\mathrm{H}_{2} \mathrm{~S}$-releasing abilities of GYY4137 were preserved. The GYY4137-loaded SF scaffolds dose-dependently released $\mathrm{H}_{2} \mathrm{~S}$ upon incubation in solution and exhibited no cytotoxic effects, in both mouse fibroblasts and human osteoprogenitor cells.

On the basis of the results obtained, we can assume that SF scaffolds loaded with concentrations of GYY4137 inside the range explored could be suitable for the proposed application. This possibility will be investigated in our future studies.

\section{AUTHOR INFORMATION}

\section{Corresponding Authors}

*E-mail: antonella.motta@unitn.it.

*E-mail: francesco.grassi@ior.it.

\section{ORCID}

Rosasilvia Raggio: 0000-0002-7442-2973

\section{Author Contributions}

\#(R.R. W.B.) These authors contributed equally to the work.

\section{Notes}

The authors declare no competing financial interest.

\section{ACKNOWLEDGMENTS}

This study was supported by grant "Ricerca Finalizzata" from the Italian Ministry of Health (RF PE-2011-02348395, title of the project "Novel approach for bone regeneration and repair using sulphur donor-based therapy").

\section{REFERENCES}

(1) Li, L.; Rose, P.; Moore, P. K. Hydrogen Sulfide and Cell Signaling. Annu. Rev. Pharmacol. Toxicol. 2011, 51 (1), 169-187.

(2) Vandiver, M. S.; Snyder, S. H. Hydrogen sulfide: A gasotransmitter of clinical relevance. J. Mol. Med. 2012, 90 (3), $255-263$.

(3) Abe, K.; Kimura, H. The possible role of hydrogen sulfide as an endogenous neuromodulator. J. Neurosci. 1996, 16 (3), 1066-1071.

(4) Koenitzer, J. R.; Isbell, T. S.; Patel, H. D.; Benavides, G. A.; Dickinson, D. A.; Patel, R. P.; Darley-usmar, V. M.; Lancaster, J. R.; Doeller, J. E.; Kraus, D. W. Hydrogen sulfide mediates vasoactivity in an $\mathrm{O}_{2}$-dependent manner. Am J Physiol Heart Circ Physiol. 2007, 292, H1953-H1960.
(5) Fiorucci, S.; Distrutti, E.; Cirino, G.; Wallace, J. L. The Emerging Roles of Hydrogen Sulfide in the Gastrointestinal Tract and Liver. Gastroenterology 2006, 131 (1), 259-271.

(6) Liu, Y.; Yang, R.; Liu, X.; Zhou, Y.; Qu, C.; Kikuiri, T.; Wang, S.; Zandi, E.; Du, J.; Ambudkar, I. S.; et al. Hydrogen sulfide maintains mesenchymal stem cell function and bone homeostasis via regulation of Ca2+ channel sulfhydration. Cell Stem Cell 2014, 15 (1), 66-78.

(7) Gambari, L.; Lisignoli, G.; Cattini, L.; Manferdini, C.; Facchini, A.; Grassi, F. Sodium hydrosulfide inhibits the differentiation of osteoclast progenitor cells via NRF2-dependent mechanism. Pharmacol. Res. 2014, 87, 99-112.

(8) Grassi, F.; Tyagi, A. M.; Calvert, J. W.; Gambari, L.; Walker, L. D.; Yu, M.; Robinson, J.; Li, J.-Y.; Lisignoli, G.; Vaccaro, C.; et al. Hydrogen Sulfide Is a Novel Regulator of Bone Formation Implicated in the Bone Loss Induced by Estrogen Deficiency. J. Bone Miner. Res. 2016, 31 (5), 949-963.

(9) Calderone, V.; Martelli, A.; Testai, L.; Citi, V.; Breschi, M. C. Using hydrogen sulfide to design and develop drugs. Expert Opin. Drug Discovery 2016, 11 (2), 163-175.

(10) Alexander, B. E.; Coles, S. J.; Fox, B. C.; Khan, T. F.; Maliszewski, J.; Perry, A.; Pitak, M. B.; Whiteman, M.; Wood, M. E. Investigating the generation of hydrogen sulfide from the phosphonamidodithioate slow-release donor GYY4137. MedChemComm 2015, 6 (9), 1649-1655.

(11) Li, L.; Whiteman, M.; Guan, Y. Y.; Neo, K. L.; Cheng, Y.; Lee, S. W.; Zhao, Y.; Baskar, R.; Tan, C.-H.; Moore, P. K. Characterization of a Novel, Water-Soluble Hydrogen Sulfide-Releasing Molecule (GYY4137): New Insights Into the Biology of Hydrogen Sulfide. Circulation 2008, 117 (18), 2351-2360.

(12) Zhao, Y.; Wang, H.; Xian, M. Cysteine-activated hydrogen sulfide (H2S) donors. J. Am. Chem. Soc. 2011, 133 (1), 15-17.

(13) Martelli, A.; Testai, L.; Citi, V.; Marino, A.; Pugliesi, I.; Barresi, E.; Nesi, G.; Rapposelli, S.; Taliani, S.; Da Settimo, F.; et al. Arylthioamides as $\mathrm{H} 2 \mathrm{~S}$ donors: L-cysteine-activated releasing properties and vascular effects in vitro and in vivo. ACS Med. Chem. Lett. 2013, 4 (10), 904-908.

(14) Li, L.; Salto-Tellez, M.; Tan, C.-H.; Whiteman, M.; Moore, P. K. GYY4137, a novel hydrogen sulfide-releasing molecule, protects against endotoxic shock in the rat. Free Radical Biol. Med. 2009, 47 (1), 103-113.

(15) Liu, Z.; Han, Y.; Li, L.; Lu, H.; Meng, G.; Li, X.; Shirhan, M.; Peh, M. T.; Xie, L.; Zhou, S.; et al. The hydrogen sulfide donor, GYY4137, exhibits anti-atherosclerotic activity in high fat fed apolipoprotein $\mathrm{E}^{(-/-)}$mice. Br. J. Pharmacol. 2013, 169 (8), 17951809.

(16) Rose, P.; Dymock, B. W.; Moore, P. K. GYY4137, a novel water-soluble, H2S-releasing molecule. Methods Enzymol. 2015, 554, 143-167.

(17) Hutmacher, D. W. Scaffolds in tissue engineering bone and cartilage. Biomaterials 2000, 21 (24), 2529-2543.

(18) Vepari, C.; Kaplan, D. L. Silk as a biomaterial. Prog. Polym. Sci. 2007, 32 (8-9), 991-1007.

(19) Rockwood, D. D. N.; Preda, R. R. C.; Yücel, T.; Wang, X.; Lovett, M. L.; Kaplan, D. L. Materials fabrication from Bombyx mori silk fibroin. Nat. Protoc. 2011, 6 (10), 1612-1631.

(20) Melke, J.; Midha, S.; Ghosh, S.; Ito, K.; Hofmann, S. Silk fibroin as biomaterial for bone tissue engineering. Acta Biomater. 2016, 31, $1-16$.

(21) Correia, C.; Bhumiratana, S.; Yan, L.-P.; Oliveira, A. L.; Gimble, J. M.; Rockwood, D.; Kaplan, D. L.; Sousa, R. A.; Reis, R. L.; VunjakNovakovic, G. Development of silk-based scaffolds for tissue engineering of bone from human adipose-derived stem cells. Acta Biomater. 2012, 8 (7), 2483-2492.

(22) Nazarov, R.; Jin, H. J.; Kaplan, D. L. Porous 3-D scaffolds from regenerated silk fibroin. Biomacromolecules 2004, 5 (3), 718-726.

(23) Kim, U. J.; Park, J.; Joo Kim, H.; Wada, M.; Kaplan, D. L. Three-dimensional aqueous-derived biomaterial scaffolds from silk fibroin. Biomaterials 2005, 26 (15), 2775-2785. 
(24) Yan, L. P.; Oliveira, J. M.; Oliveira, A. L.; Caridade, S. G.; Mano, J. F.; Reis, R. L. Macro/microporous silk fibroin scaffolds with potential for articular cartilage and meniscus tissue engineering applications. Acta Biomater. 2012, 8 (1), 289-301.

(25) Fuchs, S.; Jiang, X.; Schmidt, H.; Dohle, E.; Ghanaati, S.; Orth, C.; Hofmann, A.; Motta, A.; Migliaresi, C.; Kirkpatrick, C. J. Dynamic processes involved in the pre-vascularization of silk fibroin constructs for bone regeneration using outgrowth endothelial cells. Biomaterials 2009, 30 (7), 1329-1338.

(26) Ghanaati, S.; Unger, R. E.; Webber, M. J.; Barbeck, M.; Orth, C.; Kirkpatrick, J. A.; Booms, P.; Motta, A.; Migliaresi, C.; Sader, R. A.; et al. Scaffold vascularization in vivo driven by primary human osteoblasts in concert with host inflammatory cells. Biomaterials 2011, 32 (32), 8150-8160.

(27) Li, J. J.; Kaplan, D. L.; Zreiqat, H. Scaffold-based regeneration of skeletal tissues to meet clinical challenges. J. Mater. Chem. B 2014, 2 (42), 7272-7306.

(28) Karageorgiou, V.; Kaplan, D. L. Porosity of 3D biomaterial scaffolds and osteogenesis. Biomaterials 2005, 26 (27), 5474-5491.

(29) Maraldi, T.; Riccio, M.; Resca, E.; Pisciotta, A.; La Sala, G. B.; Ferrari, A.; Bruzzesi, G.; Motta, A.; Migliaresi, C.; Marzona, L.; et al. Human amniotic fluid stem cells seeded in fibroin scaffold produce in vivo mineralized matrix. Tissue Eng., Part A 2011, 17 (21-22), 28332843.

(30) Riccio, M.; Maraldi, T.; Pisciotta, A.; La Sala, G. B.; Ferrari, A.; Bruzzesi, G.; Motta, A.; Migliaresi, C.; De Pol, A. Fibroin scaffold repairs critical-size bone defects in vivo supported by human amniotic fluid and dental pulp stem cells. Tissue Eng., Part A 2012, 18 (9-10), $1006-1013$.

(31) Le, T. D. H.; Liaudanskaya, V.; Bonani, W.; Migliaresi, C.; Motta, A. Enhancing bioactive properties of silk fibroin with diatom particles for bone tissue engineering applications. J. Tissue Eng. Regener. Med. 2018, 12, 89.

(32) Wenk, E.; Merkle, H. P.; Meinel, L. Silk fibroin as a vehicle for drug delivery applications. J. Controlled Release 2011, 150 (2), 128141.

(33) Mourino, V.; Boccaccini, A. R. Bone tissue engineering therapeutics: controlled drug delivery in three-dimensional scaffolds. J. R. Soc., Interface 2010, 7 (43), 209-227.

(34) Mistry, B. D. A Handbook of Spectroscopic Data Chemistry, 20th ed.; Oxford Book Company: Jaipur, India, 2009.

(35) Hu, X.; Kaplan, D.; Cebe, P. Determining beta-sheet crystallinity in fibrous proteins by thermal analysis and infrared spectroscopy. Macromolecules 2006, 39 (18), 6161-6170.

(36) Bucciarelli, A.; Pal, R. K.; Maniglio, D.; Quaranta, A.; Mulloni, V.; Motta, A.; Yadavalli, V. K. Fabrication of Nanoscale Patternable Films of Silk Fibroin Using Benign Solvents. Macromol. Mater. Eng. 2017, 302 (7), 1700110.

(37) Asakura, T.; Okushita, K.; Williamson, M. P. Analysis of the structure of Bombyx mori silk fibroin by NMR. Macromolecules 2015, 48 (8), 2345-2357.

(38) Callone, E.; Dire', S.; Hu, X.; Motta, A. Processing influence on molecular assembling and structural conformations in silk fibroin: elucidation by solid state NMR. ACS Biomater. Sci. Eng. 2016, 2, 758767.

(39) Nielsen, M.; Larsen, L. H.; Ottosen, L. D. M.; Revsbech, N. P. Hydrogen microsensors with hydrogen sulfide traps. Sens. Actuators, $B$ 2015, 215, 1-8.

(40) Manferdini, C.; Gabusi, E.; Grassi, F.; Piacentini, A.; Cattini, L.; Zini, N.; Filardo, G.; Facchini, A.; Lisignoli, G. Evidence of specific characteristics and osteogenic potentiality in bone cells from tibia. J. Cell. Physiol. 2011, 226 (10), 2675-2682.

(41) Stuart, B. Biological applications of infrared spectroscopy; Ando, D., Ed.; Published on behalf of ACOL (University of Greenwich) by John Wiley; John Wiley \& Sons, Inc.: Chichester, U.K., 1997.

(42) Barth, A. Infrared spectroscopy of proteins. Biochim. Biophys. Acta, Bioenerg. 2007, 1767 (9), 1073-1101.

(43) Iizuka, E.; Yang, J. T. The Disordered and $\beta$-conformations of Silk Fibroin in Solution. Biochemistry 1968, 7 (6), 2218-2228.
(44) Zhang, H.; Li, L.-L.; Dai, F.-Y.; Zhang, H.-H.; Ni, B.; Zhou, W.; Yang, X.; Wu, Y.-Z. Preparation and characterization of silk fibroin as a biomaterial with potential for drug delivery. J. Transl. Med. 2012, 10, 117.

(45) Motta, A.; Fambri, L.; Migliaresi, C. Regenerated silk fibroin films: Thermal and dynamic mechanical analysis. Macromol. Chem. Phys. 2002, 203 (10-11), 1658-1665.

(46) Lu, Q.; Zhang, B.; Li, M.; Zuo, B.; Kaplan, D. L.; Huang, Y.; Zhu, H. Degradation mechanism and control of silk fibroin. Biomacromolecules 2011, 12 (4), 1080-1086.

(47) Motta, A.; Segnana, P.; Verin, L.; La Monica, S.; Fumarola, C.; Bucci, G.; Gussago, F.; Cantoni, A. M.; Ampollini, L.; Migliaresi, C. Physico-chemical characterization and biological evaluation of two fibroin materials. J. Tissue Eng. Regener. Med. 2014, 8 (11), 874-885.

(48) Hughes, M. N.; Centelles, M. N.; Moore, K. P. Making and working with hydrogen sulfide. Free Radical Biol. Med. 2009, 47 (10), 1346-1353.

(49) Olson, K. R. A. Practical Look at the Chemistry and Biology of Hydrogen Sulfide. Antioxid. Redox Signaling 2012, 17 (1), 32-44.

(50) Kolluru, G. K.; Shen, X.; Bir, S. C.; Kevil, C. G. Hydrogen sulfide chemical biology: Pathophysiological roles and detection. Nitric Oxide 2013, 35, 5-20.

(51) Kim, H. J.; Kim, U. J.; Leisk, G. G.; Bayan, C.; Georgakoudi, I.; Kaplan, D. L. Bone regeneration on macroporous aqueous-derived silk 3-D scaffolds. Macromol. Biosci. 2007, 7 (5), 643-655.

(52) Mi, H. Y.; Jing, X.; Salick, M. R.; Cordie, T. M.; Turng, L. S. Carbon nanotube (CNT) and nanofibrillated cellulose (NFC) reinforcement effect on thermoplastic polyurethane (TPU) scaffolds fabricated via phase separation using dimethyl sulfoxide (DMSO) as solvent. J. Mech. Behav. Biomed. Mater. 2016, 62, 417-427.

(53) Zhang, X.; Cao, C.; Ma, X.; Li, Y. Optimization of macroporous 3-D silk fibroin scaffolds by salt-leaching procedure in organic solventfree conditions. J. Mater. Sci.: Mater. Med. 2012, 23 (2), 315-324.

(54) Yao, D.; Dong, S.; Lu, Q.; Hu, X.; Kaplan, D. L.; Zhang, B.; Zhu, H. Salt-leached silk scaffolds with tunable mechanical properties. Biomacromolecules 2012, 13 (11), 3723-3729.

(55) Wilson, D.; Valluzzi, R.; Kaplan, D. L. Conformational transitions in model silk peptides. Biophys. J. 2000, 78 (5), 26902701.

(56) Tian, D.; Li, T.; Zhang, R.; Wu, Q.; Chen, T.; Sun, P.; Ramamoorthy, A. Conformations and Intermolecular Interactions in Cellulose/Silk Fibroin Blend Films: A Solid-State NMR Perspective. J. Phys. Chem. B 2017, 121 (25), 6108-6116.

(57) Deleon, E. R.; Stoy, G. F.; Olson, K. R. Passive loss of hydrogen sulfide in biological experiments. Anal. Biochem. 2012, 421 (1), 203207. 